\title{
PReS-FINAL-2108: Long-term outcome of 114 adult JIA patients in a non-pediatric rheumatology institute in Japan
}

\author{
T Miyamae ${ }^{1 *}$, E Tanaka ${ }^{1}$, T Kishi ${ }^{2}$, T Matsuyama ${ }^{1}$, T Igarashi ${ }^{3}$ S Fujikawa ${ }^{1}$, A Taniguchi ${ }^{1}$, S Momohara', S Nagata ${ }^{2}$, \\ H Yamanaka'
}

From 20th Pediatric Rheumatology European Society (PReS) Congress

Ljubljana, Slovenia. 25-29 September 2013

\section{Introduction}

The transition of adult patients with childhood-onset rheumatic disorders from pediatric to non-pediatric healthcare systems has received attention in Japan. However, the clinical course of patients transferred to non-pediatric rheumatologists has not been adequately communicated to pediatric rheumatologists.

\section{Objectives}

To evaluate the long-term outcome of patients with juvenile idiopathic arthritis (JIA) using data from a large cohort database, IORRA (Institute of Rheumatology, Rheumatoid Arthritis), managed by Tokyo Women's Medical University in Japan.

\section{Methods}

Of 182 patients identified from the IORRA database from 2000-2013, 114 were verified as having JIA based on the ILAR classification criteria. The transition of medical care, disease activity and health-related quality of life at the latest examination, and the contributions of biological disease-modifying antirheumatic drugs (DMARDs) were evaluated retrospectively.

\section{Results}

The mean age of the 114 patients at the latest examination was $36.6 \pm 13.3$ years; there were 21 males and 93 females (81.6\%). The mean age at disease onset was $11.6 \pm 3.4$ years, and disease duration was $25.0 \pm 13.3$ years. Of the 114 individuals, 106 (93.0\%) had poly- or oligoarthritis; the others had systemic JIA (sJIA). Forty-five of 105 JIA

${ }^{1}$ Institute of Rheumatology, Tokyo Women's Medical University, Tokyo, Japan Full list of author information is available at the end of the article patients (43\%) visited non-pediatric rheumatologists from disease onset, and only one-fourth were transferred from general pediatricians or pediatric rheumatologists at a median age of 20 years. Interestingly, 26 of 105 (25\%) reached transient remission in adolescence. Polyarticular JIA patients with negative rheumatoid factor (RF) showed a higher probability (41.7\%) of obtaining a transient remission compared with RF-positive polyarticular JIA patients (17.8\%). Disease activity assessed with DAS28 was significantly lower when disease onset was more recent $(3.9 \pm$ 1.3 for onset in the 1960s vs. $2.2 \pm 1.1$ for onset in the 2000s, $p=0.04$ ), with similar results shown on the SDAI, and the CDAI. The Japanese version of the Health Assessment Questionnaire (J-HAQ) also showed improvement for those with more recent onset $(1.8 \pm 1.1$ for onset in the 1960 s vs. $0.2 \pm 0.4$ for onset in the 2000 s, $\mathrm{p}<0.01$ ). The induction ratio of biological DMARDs has increased for patients with more recent disease onset, with a shorter period from disease onset to induction $(16.7 \%$ in the 1970 s, with $27.3 \pm 2.1$ years to induction vs. $80.0 \%$ in the 2000 s, with $5.6 \pm 2.3$ years to induction). Additionally, the percentage of patients requiring orthopedic surgery has decreased (53.8\% before the 1970 s vs. $10.0 \%$ in the 2000s). Two deaths, with causality attributed to the primary disease, occurred in sJIA patients who died from renal and/or cardiac failure due to amyloidosis at the ages of 27 and 38 .

\section{Conclusion}

From the viewpoint of pediatric rheumatologists, there are few opportunities to follow children beyond adolescence. The importance of transitioning care to non-pediatric rheumatologists with sufficient medical information is confirmed by the existence of a population with transient 
remission in adolescence and changes in their prognosis, with progress in rheumatology represented by biological DMARDs.

\section{Disclosure of interest}

None declared.

\section{Authors' details}

'Institute of Rheumatology, Tokyo Women's Medical University, Tokyo, Japan. ${ }^{2}$ Department of Pediatrics, Tokyo Women's Medical University, Tokyo, Japan.

${ }^{3}$ Department of Pediatrics, Nippon Medical School, Tokyo, Japan.

Published: 5 December 2013

\section{doi:10.1186/1546-0096-11-S2-P120}

Cite this article as: Miyamae et al:: PReS-FINAL-2108: Long-term

outcome of 114 adult JIA patients in a non-pediatric rheumatology

institute in Japan. Pediatric Rheumatology 2013 11(Suppl 2):P120.

Submit your next manuscript to BioMed Central and take full advantage of:

- Convenient online submission

- Thorough peer review

- No space constraints or color figure charges

- Immediate publication on acceptance

- Inclusion in PubMed, CAS, Scopus and Google Scholar

- Research which is freely available for redistribution

Submit your manuscript at www.biomedcentral.com/submit 